Journal of Energy and
Environmental Sustainability
Journal homepage : www.jees.in

\title{
Effect of Reaction Variables on Biodiesel Production from Canary Melon Seed Oil
}

\author{
${ }^{1}$ M.A. Sokoto* ${ }^{1}$ A.B. Muhammad. ${ }^{2}$ A. Sanda, ${ }^{1}$ S. Haruna, ${ }^{1}$ L.G. Hassan \\ 1. Department of Pure and Applied Chemistry, Usmanu Danfodiyo University, Sokoto \\ 2. Department of Biological Sciences, Usmanu Danfodiyo University, Sokoto
}

\section{A R T I C L E I N F O}

Received : 30 January 2018

Revised : 26 March 2018

Accepted : 10 April 2018

Keywords:

Canary melon, biodiesel,

transesterification, Optimization,

Fuel properties

\begin{abstract}
A B S T R A C T
This study explored the effect of the reaction variables in biodiesel production from canary melon seed oil using transesterification method. Oil was extracted from canary melon using soxhlet extraction method and a yield of $51.03 \%$ was obtained. General Full Factorial design was used to study the effect of the reaction variables namely catalyst concentration, $\mathrm{MeOH} /$ oil ratio, reaction temperature and reaction time. The catalyst $(\mathrm{NaOH})$ was used in varying concentrations ranging from 0.40 to $1.5 \%$ (w/ v). The molar ratios of methanol to oil studied were from 3:1 to $6: 1$. The reaction temperatures assessed were between 30 and $60^{\circ} \mathrm{C}$. The reaction time was varied from 20 minutes to 60 minutes. The highest biodiesel yield (>86\%) was obtained at reaction time of 60 minute when the $\mathrm{MeOH} /$ oil ratio was just slight over $3 \mathrm{~cm}^{3} / \mathrm{g}$ oil. Biodiesel was characterized for its fatty acid methyl ester profile using GC-MS which showed 9,12-octadecadienoic acid methyl ester (46.84\%) as the major component. The fuel properties of the biodiesel revealed its suitability as an alternative fuel for diesel engines
\end{abstract}

(C) 2018 ISEES, All rights reserved

\section{Introduction}

The growth in biodiesel production has been phenomenal in recent years. This has been associated to diminishing global oil reserves and increased awareness of the environmental impact of burning fossil fuels. Biodiesel is clean burning, non-toxic and carbon neutral with respect to contributions to atmospheric $\mathrm{CO}_{2}$. It has the advantages of being available, renewable with high cetane number and biodegradable (Dermibas, 2009). Biodiesel can be burned in existing diesel engines with no modifications and can be blended in any proportion with petroleum diesel (Knothe, 2010).

Biodiesel is usually produced by the transesterification of vegetable oil or animal fat with short chain alcohol such as methanol or ethanol. It has higher oxygen content than petroleum diesel and its use in diesel engines has shown great reductions in emission of particulate matter, carbon monoxide, sulfur, hydrocarbons, smoke and noise (Sukijit, 2013).

However, the commercialization of biodiesel is said to be hindered by high cost of feedstock for the fact that $95 \%$ of the biodiesel is synthesized from edible oils such as oils from seeds of soy bean, sunflower, and rapeseed (Knothe, 2002; Gui, et al., 2008) which may bring global imbalance to the food supply and high demand in market (Edgerton, 2009). In order to overcome this problem, search for none-edible feedstock has been the focus of many researchers (Gui et al., 2008; Kansedo et al., 2009). Thus none-edible seeds of Jatropha oil, Neem oil, Jojoba oil, Mango seed oil, Thumba oil, Mahua oil, Deccan hemp oil, Kusum oil and Rubber seed oil are currently being used for biodiesel because of their appreciable oil content (Gude et al., 2012; Chavan et al., 2014; Ramos et al., 2009; Bajpaiet and Tyagi, 2006; Ndana et al., 2011).

Canary melon plant belongs to the cucurbitaceae family and species of cucumismelo. The use of seeds of this plant as potential source of oil has been reviewed by Jacks et al. (1972). The high oil content of Canary melon seeds and its odourless characteristics could make it suitable for industrial applications. Canary melon which is grown on almost every type of soil and the seeds has the percentage oil yield of about $50.42 \%$ (Warra et al., 2015). The availability, ease of cultivations and its noncompetitiveness with food crops make it suitable for biodiesel production.

The objective of the present study is to investigate the potential of canary melon seed oil for biodiesel production and to optimize some of the variables that influence the transesterification reaction.

\subsection{Materials and Methods}

The Canary melon seeds were collected from Basawa in Zaria, Kaduna State, Nigeria. The extraction of oil from melon was carried out with $\mathrm{n}$ hexane using soxhlet extractor. The free fatty acid content in the oil was determined by titrimetric method. Two step transesterification process, i.e. acid pretreatment step followed by base catalyzed transesterification method was used to produce the biodiesel.

\subsection{Experimental Design}

The key variables examined in the study are reaction time, catalyst, methanol/oil ratio and temperature. Minitab 16 statistical software was

* Corresponding Author: abdullahimuhammadsokoto@gmail.com 
used for the design of the experiment. General Full Factorial design was used to carry out the experiment based on factor levels shown in Table 1. The experimental design matrix and resultant biodiesel yields are shown in Table 2.

Table 1: Factors and their levels for General full factorial design

\begin{tabular}{|l|l|l|l|}
\hline Factors & Low level & Mid Level & High level \\
\hline Time (min) & 20 & 40 & 60 \\
\hline Catalyst (\%) & 0.4 & 0.95 & 1.5 \\
\hline MeOH/Oil ratio & $3: 1$ & $4.5: 1$ & $6: 1$ \\
\hline Temperature $-\left({ }^{\circ} \mathrm{C}\right)$ & 30 & 45 & 60 \\
\hline
\end{tabular}

\subsection{Description of Experimental Runs}

Canary melon seed oil $(240.0 \mathrm{~g})$ was pretreated with methanol using $\mathrm{H}_{2} \mathrm{SO}_{4}$ acid catalyst $(0.05 \%)$ to convert free fatty acid to ester. The reaction was conducted at temperature of $65^{\circ} \mathrm{C}$ for 60 minutes. After esterification the alcohol layer was removed from the pretreated oil before transesterification.

Methanolic sodium hydroxide (53.1g) was poured into a flat bottom flask containing the esterified canary melon seed oil (229.3g). The mixture was refluxed at constant stirring speed then transferred into separating funnel and allowed to separate overnight under gravity. The dark bottom layer (glycerol) was drained out and the light upper layer (biodiesel) was recovered and washed with $20 \%$ volume of warm distilled water and agitated gently for 5 minutes. The mixture was allowed to settle into twolayers from which the biodiesel was separated. The process was repeated two times to give a clearer ester. The washed biodiesel was dried over anhydrous sodium sulphate and weighed (Meher et al., 2006). The same experimental procedure was used for other runs based on the experimental conditions shown in Table 2 . The percentage biodiesel yield was calculated using equation (1).

$$
\text { Biodiesel yield }=\frac{\text { Actual weight }}{\text { Theoritical weight }} \times 100
$$

\subsection{Data Analysis}

Analysis of variance was performed to determine factors that are statistically significant and regression analysis was used to fit the model in equation (2).

$\mathrm{Y}=\mathrm{K}+\mathrm{a}_{1} \mathrm{~A}+\mathrm{b}_{1} \mathrm{~B}+\mathrm{c}_{1} \mathrm{C}+\mathrm{d}_{1} \mathrm{D}+\mathrm{a}_{2} \mathrm{~A}^{2}+\mathrm{b}_{2} \mathrm{~B}^{2}+\mathrm{c}_{2} \mathrm{C}^{2}+\mathrm{d}_{2} \mathrm{D}^{2}+\mathrm{a}_{3} \mathrm{AB}+$

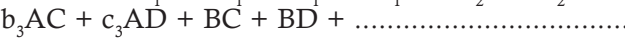

Where $\mathrm{Y}$ is the predicted response (dependent variable), $\mathrm{K}$ is constant.

$a_{1}, b_{1}, c_{1} d_{1}, a_{2}, b_{2}, c_{2} d_{2} a_{3} b_{3}, c_{3}$ are coefficients of the factors. A, B, C and $\mathrm{D}$ are the Factors. $\mathrm{AB}, \mathrm{AC}, \mathrm{BC}, \mathrm{AD}, \mathrm{CD}$ and $\mathrm{BD}$ are Interaction between the factors.

\section{$2.4 \quad$ Fuel Properties of the Biodiesel}

The properties of biodiesel including specific gravity $\left(\mathrm{g} / \mathrm{cm}^{3}\right)$ at $15^{\circ} \mathrm{C}$ (D1298), viscosity at $40^{\circ} \mathrm{C}$ (Cst) (D445), flash Point $\left({ }^{\circ} \mathrm{C}\right)(\mathrm{D} 93)$, cloud point $\left({ }^{\circ} \mathrm{C}\right)(\mathrm{D} 1500)$, pour point $\left({ }^{\circ} \mathrm{C}\right)(\mathrm{D} 97)$, diesel index (D611), API gravity, colour comparator (D1500), aniline point $\left({ }^{\circ} \mathrm{C}\right)(\mathrm{D} 611)$, cetane number were determined using ASTM methods.

\subsection{GC-MS Analysis}

A QP- 2010 model GC-MS machine was used for the characterizations of fatty acid methyl esters in the produced biodiesel. The technique involves separation of alkyl esters in the mixture into their components based on boiling point and polarity. In the conduct of the analysis, 2 il (micro liters) of the derivatized sample was injected into the gas chromatograph which its oven temperature program between $60^{\circ} \mathrm{C}-280^{\circ} \mathrm{C}$ at $5^{\circ} \mathrm{C} / \mathrm{min}$ holding time. The injected sample in the gas chromatograph, separated on a column (a column is a long, thin path (capillary) tube that contains a material with which the sample components interact more or less strongly depending on their structure (polarity) while it is heated). Helium gas was used as a carrier gas and flame ionization detector (FID) as a detector.

\subsection{Results and Discussion}

The experimental matrix for the general full factorial design and the biodiesel yields from the canary melon seed oil transesterification are shown in Table 2. The estimated coefficient and analysis of variance for the response are shown in Tables 3 and 4, respectively.
Table 2: Experimental Matrix for the General Full Factorial Design and \% Biodiesel Yield of Canary Melon Seed Oil

\begin{tabular}{|c|c|c|c|c|}
\hline $\begin{array}{l}\mathrm{MeOH} / \\
\text { oil ratio } \\
\left(\mathrm{cm}^{3} / \mathrm{g}\right)\end{array}$ & $\begin{array}{l}\text { Catalyst } \\
(\%)\end{array}$ & $\begin{array}{l}\text { Temperature } \\
\left({ }^{\circ} \mathrm{C}\right)\end{array}$ & $\begin{array}{l}\text { Time } \\
(\min )\end{array}$ & $\begin{array}{l}\text { Yield } \\
(\%)\end{array}$ \\
\hline 6.0 & 0.40 & 60 & 60 & 93 \\
\hline 6.0 & 1.50 & 30 & 20 & 80 \\
\hline 6.0 & 1.50 & 30 & 20 & 83 \\
\hline 6.0 & 0.40 & 30 & 60 & 84 \\
\hline 3.0 & 1.50 & 60 & 60 & 88 \\
\hline 6.0 & 1.50 & 60 & 60 & 82 \\
\hline 3.0 & 0.40 & 60 & 60 & 86 \\
\hline 3.0 & 0.40 & 60 & 20 & 92 \\
\hline 3.0 & 1.50 & 30 & 20 & 83 \\
\hline 4.5 & 0.95 & 45 & 40 & 79 \\
\hline 3.0 & 1.50 & 30 & 60 & 90 \\
\hline 3.0 & 0.40 & 30 & 20 & 75 \\
\hline 3.0 & 1.50 & 60 & 20 & 88 \\
\hline 3.0 & 0.40 & 30 & 60 & 84 \\
\hline 3.0 & 1.50 & 60 & 60 & 90 \\
\hline 3.0 & 1.50 & 30 & 20 & 81 \\
\hline 4.5 & 0.95 & 45 & 40 & 79 \\
\hline 6.0 & 0.40 & 60 & 20 & 82 \\
\hline 3.0 & 1.50 & 60 & 20 & 86 \\
\hline 6.0 & 1.50 & 30 & 60 & 80 \\
\hline 3.0 & 0.40 & 30 & 60 & 86 \\
\hline 6.0 & 1.50 & 60 & 20 & 78 \\
\hline 6.0 & 0.40 & 30 & 20 & 83 \\
\hline 6.0 & 1.50 & 60 & 20 & 82 \\
\hline 6.0 & 1.50 & 30 & 60 & 85 \\
\hline 3.0 & 0.40 & 60 & 20 & 90 \\
\hline 3.0 & 0.40 & 30 & 20 & 75 \\
\hline 3.0 & 0.40 & 60 & 60 & 88 \\
\hline 4.5 & 0.95 & 45 & 40 & 77 \\
\hline 6.0 & 0.40 & 30 & 60 & 75 \\
\hline 3.0 & 1.50 & 30 & 60 & 88 \\
\hline 6.0 & 1.50 & 60 & 60 & 85 \\
\hline 6.0 & 1.50 & 60 & 20 & 80 \\
\hline 6.0 & 0.40 & 60 & 60 & 92 \\
\hline 6.0 & 0.40 & 30 & 20 & 78 \\
\hline
\end{tabular}

\subsection{Effect of Reaction Variable on Biodiesel Yield (\%)}

Figure 1a shows the effect of $\mathrm{MeOH} /$ oil ratio and time on the biodiesel yield while temperature was held at $30^{\circ} \mathrm{C}$. It can be seen from the plot (Figure 1a) that biodiesel yield increases with increase in the reaction time and decrease in the $\mathrm{MeOH} /$ oil ratio, such that high yields (>86\%) at reaction time of 60 minute when the $\mathrm{MeOH} /$ oil ratio is just slight over 3 $\mathrm{cm}^{3} / \mathrm{g}$ oil. It can be observed from Figure 1a that, when the methanol to oil ratio was increased further beyond an optimum amount $\left(3.3 \mathrm{~cm}^{3} / \mathrm{g}\right)$, the biodiesel yield slightly decreased. The decrease in the biodiesel could be due to dissolution of glycerol produced as by-product in the excess methanol, which inhibited the biodiesel reaction on the surface of the catalyst by shifting the equilibrium in the reverse direction (Hasni et al., 2017). Also, the polar hydroxyl group in methanol could act as emulsifier, which further hinders the separation of the biodiesel product from glycerol (Yatish 2018), hence, reduce the methyl esters production.

Figure $1 \mathrm{~b}$ further shows when the $\mathrm{MeOH} /$ oil ratio was held at $3 \mathrm{~cm}^{3} /$ $\mathrm{g}$, relatively lower yields $(<80 \%)$ of the biodiesel was obtained after 20 minutes of reaction at $30{ }^{\circ} \mathrm{C}$. But at $60{ }^{\circ} \mathrm{C}$ the yield increases to $>88 \%$ for same reaction time of 20 minutes. It could be deduced from the figure $1 \mathrm{~b}$ that, an increase in reaction time decreases the percentage biodiesel yield. The observed decreased in the biodiesel implies that the reversible reaction is favoured with more reaction period. According to Hindryawati et al, 
(2014) long reaction time causes reduction in esters yield due to ester hydrolysis and soap formation.

The effect of temperature and $\mathrm{MeOH} /$ oil ratio on the biodiesel yield while time was held at 20 minute is shown on Figure 1c, which, in agreement with Figure 1a, that shows high methyl ester yields are obtained at $\mathrm{MeOH} /$ oil ratio of about $3 \mathrm{~cm}^{3} / \mathrm{g}$ when reaction temperature was above $50{ }^{\circ} \mathrm{C}$. The biodiesel production process is a reversible reaction and proceeds favourably through endothermic reaction condition, thus, high temperature favour the shift of the reaction equilibrium toward the maximum esters production (Yu et al., 2011). It was noted that the biodiesel yield increased significantly as the reaction temperature was increased and maximum methyl ester conversion can be obtained for high reaction temperature compared to the lower temperatures (Bhaskar et al., 2018). At high temperature, the collision among the reactant molecules increases due to increase in kinetic energy, hence enhance the miscibility and mass transfer between the reactants (Nizah et al, 2014). Also at high temperature, the observed increase in biodiesel yield is likely due to the increases immiscibility of the reactants, decreases in viscosity of the reaction mixture with temperature and enhanced dispersion of catalyst particles in liquid medium with increase in temperature (Ngoya et al., 2017).

The results obtained in the present study agreed with the finding in literature. Leung and Guo (2006) and Eevera et al. (2009) found that increases of the reaction temperature beyond the optimal level, decreases the yield of the biodiesel because the higher reaction temperature accelerates the saponification reaction of triglycerides. The reaction temperature must be less than the boiling point of alcohol in order to ensure that the alcohol will be not leaked out through vaporization. The optimal temperature ranges depends on the oil used (Leung and Guo 2006). Ma and Hanna (1999) stated that higher temperature and longer period will burn the alcohol and will reduce the methyl ester yield.

\subsection{Analysis of Variance (ANOVA)}

The statistical analysis of variance (ANOVA) was carried out to evaluate the significance and fitness of the model as well as the impact of individual factors and their interaction on the chosen response. The results of ANOVA are presented in Table 3. Results of the analysis of variance (Table 3) indicate that all the linear terms are significant except catalyst concentration. Two $\left(c^{*} m\right.$ and $\left.c^{*} d\right)$ out of six interactions were found to be significant. Amongst the three way interactions only that involving time, methanol/oil ratio and temperature affect the biodiesel yield significantly. The four way interaction and centre points were also significant. Equation 3 (based on coded coefficients) was obtained following removal of the insignificant terms.

Yield $(\%)=83.229+1.250 t+0.000 c-2.125 m+2.688 d-0.937 c^{*} m$ $-1.750 c^{*} d+2.562 t^{*} m^{*} d-1.000 t^{*} c^{*} m^{*} d$

The estimated effect shows that all the terms are significant including the center point (ct pt). The analysis of variance shows that the values of the determination coefficient (R-sq) and the adjusted coefficient $\left(\mathrm{R}^{2} \mathrm{adj}\right)$ were found to be $94.74 \%$ and $90.06 \%$, respectively. After removing the non-significant terms, the significant terms were reanalyzed giving the determination coefficient (R-sq) and the adjusted coefficient $\left(R^{2} a d j\right)$ of $75.66 \%$ and $71.47 \%$ which shows that the model fitted the experimental results quite well

\section{3: Fatty Acid Methyl Esters Profile Biodiesel}

The GC-MS analysis of canary melon biodiesel shows the profile of the fatty acid methyl esters (FAMEs) in the produced biodiesel. The FAMEs in the canary melon seed biodiesel is mainly composed of 9,12 octadecadienoic methyl ester (46.84\%), hexadecanoic acid methyl ester $(13.30 \%)$, octadecanoic acid methyl ester $(8.14 \%)$, octadecenoic acid methyl ester $(0.83 \%)$, eicosanoic acid methyl ester( $3.79 \%)$, eicosatrienoic acid methyl ester (3.34\%), 9-octadecenoic acid methyl esters (3.88\%), Docosenoic acid methyl ester (3.00\%) and traces of other none methyl ester. The composition of the FAMEs indicate that 9, 12-octadecadienoic acid methyl (46.84\%) is most dominant ester in the canary melon biodiesel.

The FAMEs profile of the canary melon seed biodiesel has unsaturated methyl esters content of $66.07 \%$. The high proportion of the unsaturated methyl esters in the produced biodiesel contributes to the improved cold flow properties. However, the total saturated fatty acid methyl ester content of the canary melon biodiesel constitutes $28.23 \%$ of the total methyl esters. Saturated FAMES in the produced biodiesel would contribute to the improved oxidation stability. The composition of FAMES in biodiesel would make the produced diesel to have improved the oxidation stability and cold flow properties. This can be explained that the content of unsaturated fatty acids are sensitive to oxidative degradation, as well as unsaturated fatty compounds have lower melting points than unsaturated fatty compounds (Chandra - Sekhar et al., 2018). The

\section{Contour Plots of Yeild (\%)}
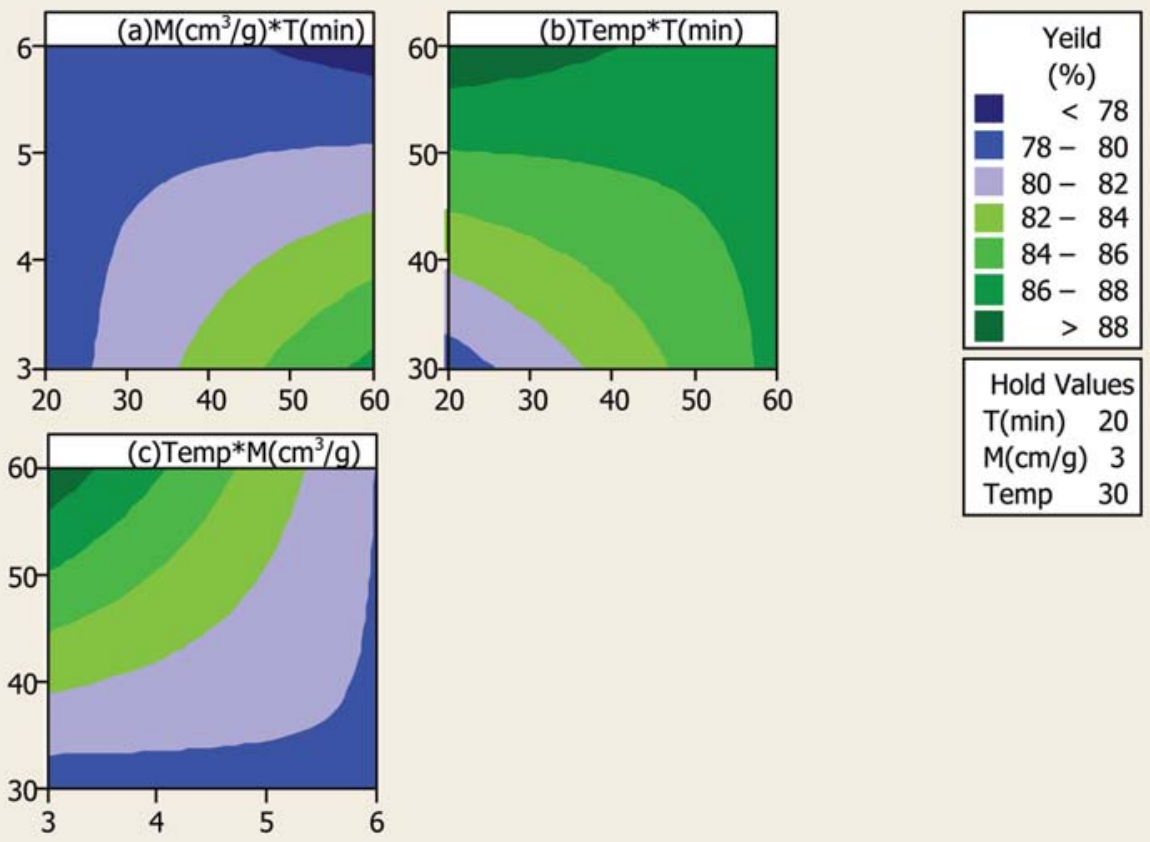

Figure 1: The Contour Plot of Biodiesel Yield (\%) against interactions of reaction variables (a) MeOH/Oil Ratio*Time (b) Temperature*Time, (c) Temperature* $\mathrm{MeOH} /$ Oil Ratio) 
Table 3: Analysis of Variance for the biodiesel yield from Canary melon seed oil

\begin{tabular}{|c|c|c|c|c|c|c|c|}
\hline Source & DF & SeqSS & AdjSS & AdjMS & $\mathbf{F}$ & $\mathbf{P}$ & Significance \\
\hline $\mathrm{A}(\mathrm{min})$ & 1 & 50.000 & 50.000 & 50.000 & 18.12 & 0.000 & $\mathrm{~S}$ \\
\hline B (M) & 1 & 0.000 & 0.000 & 0.000 & 0.000 & 1.000 & ns \\
\hline C (\%) & 1 & 144.500 & 144.500 & 144.500 & 52.37 & 0.000 & $\mathrm{~s}$ \\
\hline $\mathrm{D}\left({ }^{\mathrm{o}} \mathrm{c}\right)$ & 1 & 231.125 & 231.125 & 231.125 & 83.76 & 0.000 & $\mathrm{~s}$ \\
\hline $\mathrm{A}(\min ) * \mathrm{~B}(\mathrm{M})$ & 1 & 0.125 & 0.125 & 0.125 & 0.05 & 0.834 & ns \\
\hline $\mathrm{A}(\min ) * \mathrm{C}(\%)$ & 1 & 6.125 & 6.125 & 6.125 & 2.22 & 0.154 & ns \\
\hline $\mathrm{A}(\mathrm{min}) * \mathrm{D}\left({ }^{\mathrm{o}} \mathrm{c}\right)$ & 1 & 4.500 & 2.500 & 4.500 & 1.63 & 0.218 & ns \\
\hline $\mathrm{B}(\mathrm{M}) * \mathrm{C}(\%)$ & 1 & 28.125 & 28.125 & 28.125 & 10.19 & 0.005 & $\mathrm{~s}$ \\
\hline $\mathrm{B}(\mathrm{M}) * \mathrm{D}\left({ }^{\mathrm{o}} \mathrm{c}\right)$ & 1 & 98.000 & 98.000 & 98.000 & 35.52 & 0.000 & $\mathrm{~s}$ \\
\hline $\mathrm{C}(\%)^{*} \mathrm{D}\left({ }^{\mathrm{o}} \mathrm{c}\right)$ & 1 & 0.000 & 0.000 & 0.000 & 0.00 & 1.000 & ns \\
\hline $\mathrm{A}(\min ) * \mathrm{~B}(\mathrm{M}) * \mathrm{C}(\%)$ & 1 & 8.000 & 8.000 & 8.000 & 2.90 & 0.106 & ns \\
\hline $\mathrm{A}(\mathrm{min}) * \mathrm{~B}(\mathrm{M}) * \mathrm{D}\left({ }^{\circ} \mathrm{c}\right)$ & 1 & 0.125 & 0.125 & 0.125 & 0.05 & 0.834 & ns \\
\hline $\mathrm{A}(\mathrm{min}) * \mathrm{C}(\mathrm{cm} / \mathrm{g}) * \mathrm{D}\left({ }^{\circ} \mathrm{c}\right)$ & 1 & 210.125 & 210.125 & 210.125 & 76.15 & 0.000 & $\mathrm{~s}$ \\
\hline $\mathrm{B}(\mathrm{M}) * \mathrm{C}(\mathrm{cm} / \mathrm{g}) * \mathrm{D}\left({ }^{\mathrm{o}} \mathrm{c}\right)$ & 1 & 3.125 & 3.125 & 3.125 & 1.13 & 0.301 & ns \\
\hline $\mathrm{A}(\mathrm{min}) * \mathrm{~B}(\mathrm{M}) * \mathrm{C}(\mathrm{cm} / \mathrm{g}) * \mathrm{D}\left({ }^{\circ} \mathrm{c}\right)$ & 1 & 32.000 & 32.000 & 32.000 & 11.60 & 0.003 & $\mathrm{~s}$ \\
\hline Error & 18 & 49.667 & 49.667 & 21.259 & & & \\
\hline Total & 34 & 944.121 & & & & & \\
\hline
\end{tabular}

Where $\mathrm{A}(\mathrm{min})=$ Time, $\mathrm{B}(\mathrm{M})=$ Catalyst, $\mathrm{C}(\mathrm{cm} / \mathrm{g})=\mathrm{MeOH} /$ Oil ratio, $\mathrm{D}\left({ }^{\circ} \mathrm{C}\right)=$ Temperature $\mathrm{s}=$ significant, ns $=$ not significant, $\mathrm{R}-\mathrm{sq}=94.74 \% \mathrm{R}-\mathrm{sq}$ $($ adj $)=90.06 \%$.

Table 4: Estimated Effects and Coefficient for Biodiesel Yield of Canary melon seed oil

\begin{tabular}{|lc|l|l|ll|l|}
\hline Terms & Effect & Coef & SE Coef & $\mathrm{T}$ & $\mathrm{P}$ & Significance \\
\hline Constant & & 83.688 & 0.4976 & 168.18 & 0.000 & $\mathrm{~S}$ \\
$\mathrm{~A}(\mathrm{~min})$ & 2.500 & 1.250 & 0.4976 & 2.51 & 0.018 & $\mathrm{~S}$ \\
$\mathrm{C}(\mathrm{cm} / \mathrm{g})$ & -4.250 & -2.125 & 0.4976 & -4.27 & 0.000 & $\mathrm{~S}$ \\
$\mathrm{D}\left({ }^{\mathrm{O}} \mathrm{C}\right)$ & 5.375 & 2.688 & 0.4976 & 5.40 & 0.000 & $\mathrm{~S}$ \\
$\mathrm{~A}(\mathrm{~min}) * \mathrm{C}(\%) * \mathrm{D}\left({ }^{\mathrm{O}} \mathrm{C}\right)$ & 5.125 & 2.563 & 0.4976 & 5.15 & 0.000 & $\mathrm{~S}$ \\
$\mathrm{Ct} \mathrm{pt}$ & & -5.354 & 1.6997 & -3.15 & 0.004 & $\mathrm{~S}$ \\
& & & & & &
\end{tabular}

Where $\mathrm{A}(\mathrm{min})=$ Time, $\mathrm{C}(\mathrm{cm} / \mathrm{g})=\mathrm{MeOH} /$ Oil ratio, $\mathrm{D}\left({ }^{\circ} \mathrm{C}\right)=$ Temperature, $\mathrm{S}=$ significant, $\mathrm{R}-\mathrm{sq}=75.66 \%$ and $\mathrm{R}-\mathrm{sq}(\operatorname{adj})=71.47 \%$.

proportion of saturated and unsaturated FAMEs in the canary melon seed oil concurred with fatty acid methyl ester composition reported for Schleichera oleosa oil biodiesel (Silitonga et al., 2015), mixed Jatropha curcas-ceiba pentendra biodiesel (Dharma et al., 2016)

It could be deduce that from the FAMEs profile that the canary melon seed oil posses some useful characteristic as a good feedstock for biodiesel.

\section{4: Fuel Properties of the Biodiesel}

Fuel properties of biodiesel indicate the quality of fuel and their impact on engine. These properties include viscosity, cetane number, density, flash point, cloud and pour points, among other. The fuel properties of canary melon seed oil biodiesel is displayed in Table 6 . 
Table 6: Properties of canary melon seed biodiesel

\begin{tabular}{lll}
\hline Parameter & Values & *ASTM standard \\
\hline Specific gravity $\left(\mathrm{g} / \mathrm{cm}^{3}\right)$ at $15^{\circ} \mathrm{C}$ & $0.8937 \pm 0.10$ & 0.90 \\
Viscosity at $40^{\circ} \mathrm{C}(\mathrm{Cst})$ & $5.74 \pm 0.12$ & $1.9-6.0$ \\
Flash Point $\left({ }^{\circ} \mathrm{C}\right)$ & $108 \pm 0.06$ & $100-170$ \\
Cloud point $\left({ }^{\circ} \mathrm{C}\right)$ & $3 \pm 0.02$ & $-3-2$ \\
Pour point $\left({ }^{\circ} \mathrm{C}\right)$ & $3 \pm 0.01$ & $-15-10$ \\
Diesel index & 32.73 & \\
API Gravity & 26.83 & \\
Color comparator & 1.0 & \\
Aniline point $\left({ }^{\circ} \mathrm{C}\right)$ & 50 & $48-65$ \\
Cetane number & 33.56 & \\
\hline
\end{tabular}

Source: *Gerpen et al. (2004) and Kaduna petroleum and petrol chemicals

The specific gravity $\left(0.8937 \mathrm{~g} / \mathrm{cm}^{3}\right)$ of the canary melon biodiesel is higher than that of cotton seed oil $\left(0.8817 \mathrm{~g} / \mathrm{cm}^{3}\right)$ biodiesel reported by Onukwuli et al., (2017), although the values were within the acceptable range of $0.80-0.90$ recommended by ASTM. Specific gravity also allows biodiesel to be blended with petroleum diesel in order to improve engine performance and emission properties. The API gravity (26.83) of canary melon biodiesel shows the amount of heating value of energy released upon the combustion of the fuel.

The flash point of canary melon biodiesel $\left(108^{\circ} \mathrm{C}\right)$ is lower than that of cotton seed oil biodiesel of $173^{\circ} \mathrm{C}$ as reported by Onukwuli et al., (2017). The flash point of canary melon biodiesel is within the recommended limit of ASTM standard $\left(100^{\circ} \mathrm{C}-170^{\circ} \mathrm{C}\right)$. The high value obtained in this study clearly signifies that the biodiesel produce is free from methanol. This is because methanol can reduce the flash point and also negatively affect the diesel engine parts such as seal, elastomers and fuel pumps (Sokoto et al., 2011)

The pour point obtained $\left(3^{\circ} \mathrm{C}\right)$ obtained from canary melon biodiesel is lower than the value $\left(5^{\circ} \mathrm{C}\right)$ reported for cotton seed oil biodiesel by Onukwuli et al., (2017) but higher than $-2^{\circ} \mathrm{C}$ reported for Jatropha by Raja et al. (2011). The cloud point of canary melon seed oil biodiesel $\left(3.0^{\circ} \mathrm{C}\right)$ is higher than the cloud points of hazelnut (-11) and sunflower biodiesel (-15) as reported by Saydut et al. (2016). There is no limit described in ASTM D 6751 for cloud point of biodiesel as per specification, but the cloud point of canary melon biodiesel implies that it can be used in a cold region without possible risk of solidification.

Viscosity is an important property of biodiesel that influence the operation of fuel injection particularly at low temperature. The viscosity (5.72 cst) of canary melon biodiesel is within the ASTM recommended values. The viscosity value obtained in the present study is lower than the viscosity of cotton seed biodiesel $\left(6.81 \mathrm{~mm}^{2} / \mathrm{s}\right)$ (Onukwuli et al., 2017); but higher than the viscosity $\left(3.556 \mathrm{~mm}^{2} / \mathrm{s}\right)$ for Brucea javanica methyl esters (Hasni et al., 2017). High viscosity of the fuels produces larger drops of fuel in an engine combustion chamber which may not burn as a clean fuel. Also high viscosity affects the fluidity of the fuel and leads to poor atomization of the fuel spray and improper operation of fuel injectors. Canary melon biodiesel have suitable viscosity that could suit the vehicle fuel injection system.

The aniline point $\left(50^{\circ} \mathrm{C}\right)$ for Canary melon seed biodiesel which is higher than $33.89^{\circ} \mathrm{C}$ and $34.4^{\circ} \mathrm{C}$ reported for both soy oil biodiesel and jatropha biodiesel by Ndana et al. (2011). This shows that the biodiesel is miscible with other aromatic fuel.

Cetane number signifies the ignition delay time of the fuel on its injection into the combustion chamber. A higher cetane number of esters is desired, which is an indication of short ignition delay. The cetane number of canary melon biodiesel was found to be 33.56 which is lower than the centane number for hazelnut oil biodiesel (53.35) and sunflower oil biodiesel (51.25) reported by Saydut et al. (2016). Low cetane numbers have been associated with higher percentage of unsaturated components (C 18:2 and C 18:3) in the biodiesel. The FAMEs profile of canary melon have unsaturated methyl esters as the dominant esters.

The canary melon biodiesel have a ASTM color (1.0) which correspond to that of soy beans biodiesel (1.0) ( Ndana et al.,2011). The result implies that the canary melon biodiesel have an acceptable colour which is within the ASTM colour scale $(0.5$ - 8.0).

\section{Conclusion}

The effect of reaction variables and their interaction on the transesterification of canary melon seed oil has been studied. The result revealed that oil conversion varies within a given reaction temperature and time. A higher reaction temperature can increase reaction rate. For shorter time and lower catalyst concentration, higher temperature can speed up the transesterification process. The result also shows that high concentration of catalyst does not favor transesterification reaction. Reasonable amount of $\mathrm{MeOH} /$ oil ratio is required in the transesterification of the oil. Biodiesel produced from canary melon seed oil has compatible properties for conventional diesel engines. The FAMEs profile of the canary melon seed biodiesel has unsaturated and methyl esters content of $66.07 \%$ and $28.23 \%$ respectively. The FAMEs profile of biodiesel from the canary melon seed oil show that it has some useful characteristic that can improve oxidation stability and cold flow properties.

\section{References}

[1] Bajpai D, Tyagi VK, 2006, Biodiesel: Source, production, composition, properties and its benefits. Journal Oleo Science, 55: 487-502.

[2] Baskar ,G., I. Aberna Ebenezer Selvakumari, R. Aiswarya, 2018, Biodiese production from castor oil using heterogeneous Ni doped $\mathrm{ZnO}$ nanocatalyst. Bioresource Technology 250: 793-798

[3] Chandra - Sekhar S., K. Karuppasamy, N. Vedaraman, A.E. Kabeel, Ravishankar Sathyamurthy, Medhat Elkelawy, Hagar Alm ElDin Bastawissi, 2018, Biodiese production process optimization from Pithecellobium dulce seed oil: Performance, combustion, and emission analysis on compression ignition engine fuelled with diesel/biodiesel blends. Energy Conversion and Management 161:141-154

[4] Chavan SB, Kumbhar RR, Sharma YC, 2014, Transesterification of Citrulluscolocynthis (Thumba) oil: Optimization for Biodiesel Production. Advance. Applied Science Research, 5(3): 10-20.

[5] Dermibas A, 2009, Biodiesel from Waste Cooking Oil via Base-Catalytic and Supercritical Method Transesterification. Energy Conversion Management, 50(4): $923-927$.

[6] Dharma, S., H.H. Masjuki, Hwai Chyuan Ong, A.H. Sebayang, A.S. Silitonga, F. Kusumo,T.M.I. Mahlia, 2016, Optimization of biodiesel production process for mixed Jatropha curcas - Ceiba pentandra biodiesel using response surface methodology Energy Conversion and Management 115: 178-190

[7] Edgerton MD, 2009, Increasing Crop Productivity to Meet Global Needs for Feed, Food and Fuel. Journal of Plant Physiology, 149(1): 7-13.

[8] Eevera T, Rajendran K, Saradha S, 2009, Biodiesel production process optimization and characterization to assess the suitability of the product for varied environmental conditions. Renew Energy, 34(3):762-5.

[9] Freedman B, Pryde EH, Mounts TL, 1984, Variables Affecting the Yield of Fatty Esters from Transesterified Vegetable Oils. Journal of American Oil and Chemist Society, 61(10): 1638.

[10] Gude VG, Patil PD, Grant G E, Deng S, 2012, Sustainable Biodiesel Production, Second world Sustainable forum,1-14, Postfach 4020 Basel, Switzerland www.wsforum.org Retrieved on 26, June 2016.

[11] Gui MM, Lee KT, Bhatia S, 2008, Feasibilily of Edible Oil vs. Non-edible vs. Waste Edible Oils as Biodiesel Feedstock. Energy, 33: 1646-1653

[12] Hasni Khalil, Zul Ilham, Surya Dharma , Mahendra Varman, 2017, Optimization of biodiesel production from Brucea javanica seeds oil as novel non-edible feedstock using response surface methodology Energy Conversion and Management 149: 392- 400

[13] Hindryawati Noor N., G.P.Md. Maniam, R. Karim, K.F. Chong, 2014, Transesterification of used cooking oil over alkali metal (Li, Na,K) supported rice husk silica as potential solid base catalyst, Eng.Sci. Technol. Int. J. 17: 95 -103. 
[14] Kansedo J, Lee KT, Bhatia S, 2009, Cerbera Odollam (Sea Mango) Oil as a Promising Non-edible Feedstock for Biodiesel Production. Fuel, 88:1148-1150.

[15] Knothe G, 2009, Improving Biodiesel Fuel properties by modifying fatty Esters composition. Journal of Energy and Environmental Science 10: 1039- 1054

[16] Knothe G, 2002, Current Perspectives on Biodiesel. Inform, 13: 900-903.

[17] Knothe G, 2010, Biodiesel and Renewable Diesel: A Comparison. Progress in Energy \& Combustion Science, 36(3): 364-373.

[18] Leung DYC, Guo Y, 2006, Transesterification of neat and used frying oil: optimization for biodiesel production. Fuel Process Technol ;87(10):883-90.

[19] Ma F, Hanna M A, 1999, Biodiesel Production: a review. Bioresource Technology, 70: 1-15.

[20] Meher LC, Vidya, SS, Naik SN, 2006, Optimization of Alkali Catalyzed Transesterification of Pongania pinnata for Production of Biodiesel. Bioresource Technology, 97 (12): 1392.

[21] Ndana M, Garba B, Hassan LG, Faruk, UZ, 2011, Evaluation of Physcochemical Properties of Biodiesel Produced from Some Veg. Oils in Nigeria Origin. Bayaro Journal of Pure \& Applied Sciences, 4 (1): 67-71.

[22] Ngoya ,T., F.A. Elizabeth, O. Oluwaseun,2017, Optimisation of biodiesel production from waste vegetable oil and eggshell ash. South. J. Chem. Eng. 23:14556.

[23] Nizah M.F. Rabiah, Y.H. Taufiq-Yap, U. Rashid, S.H. Teo, Z.A. Shajaratun Nur, A Islam, 2014, Production of biodiesel from non-edible Jatropha curcas oil via transesterification using $\mathrm{Bi}_{2} \mathrm{O}_{3}-\mathrm{La}_{2} \mathrm{O}_{3}$ catalyst, Energy Conversion and Management, 88: 1257-1262

[24] Onukwuli Dominic Okechukwu, Lovet Nwanneka Emembolu, Callistus Nonso Ude, Sandra Ogechukwu Aliozo , Mathew Chukwudi Menkiti, 2017, Optimization of biodiesel production from refined cotton seed oil and its characterization Egyptian Journal of Petroleum 26, 103-110
[25] Raja AS, Robinson Smart DS, Lindon Robert L C, 2011, Biodiesel Production from Jatropha Oil and its Characterization, Research Journal Chemical Science, 1 (1): 81-87.

[26] Ramos MJ, Fernandez CM, Casas A, Rodriguez L, Perez A, 2009, Influence of Fatty Acid Composition of Raw Materials on Biodiesel Properties. Bioresource Technology, 100: 261-268.

[27] Saydut Abdurrahman, Sait Erdogan, Aylin Beycar Kafadar, Canan Kaya, Firat Aydin, Candan Hamamci, 2016, Process optimization for production of biodiesel from hazelnut oil, sunflower oil and their hybrid feedstock. Fuel 183: 512-517

[28] Silitonga A.S., H.H. Masjuki , T.M.I. Mahlia, Hwai Chyuan Ong , F. Kusumo, H.B Aditiya, N.N.N. Ghazali, 2015, Schleichera oleosa L oil as feedstock for biodiese production. Fuel 156: 63-70

[29] Sokoto MA, Hassan LG, Dangoggo SM, Gwandu HA, Uba A, 2011, Influence of Fatty Acid Methyl Esters on Fuel properties of Biodiesel produced from the seeds Oil of Curcuvita pepo. Nigerian Journal of Basic and Applied Sciences, 19(1): 81-86.

[30] Sukjit T, Punsuvon V, 2013, Process Optimization of Crude Palm Oil Biodiese Production by Response Surface Methodology. European International Journal of Science and Technology, 2(7): 49-56.

[31] Warra, AA, Sheshi F, Hammad SA, Ahamed A, 2015, Soap Production from Characterized Canary Melon (C.Melo) Seed Oil. International Journal of Pharmaceutical Chemistry and Toxicology. 1(1); 14-23.

[32] Yatish KV, Lalithamba HS, Suresh R, Harsha Hebbar HR, 2018, Optimization of bauhinia variegata biodiesel production and its performance, combustion and emission study on diesel engine, Renewable Energy, doi: 10.1016/ j.renene.2018.01.124

[33] Yu, Z. Wen, H. Li, S.-T. Tu, J. Yan, 2011, Transesterification of Pistacia chinensis oil for biodiesel catalyzed by $\mathrm{CaO}-\mathrm{CeO}_{2}$ mixed oxides, Fuel, 90: 1868-1874. 